\title{
Evaluation of the reporting quality of guidelines for gastric cancer using the RIGHT checklist
}

\author{
Xuan $\mathrm{Wu}^{1 \#}$, Ding $\mathrm{Li}^{2 \#}$, Haiyang Chen ${ }^{1 \#}$, Jing $\mathrm{Han}^{1}$, Hanqiong Zhou ${ }^{1}$, Zhen $\mathrm{He}^{1}$, Yanfang $\mathrm{Ma}^{3}$, \\ Bingqi Dong ${ }^{4}$, Yingxi Wu ${ }^{1}$, Kristina A. Matkowskyj ${ }^{5}$, Aslam Ejaz ${ }^{6}$, Khaldoun Almhanna ${ }^{7}$, Qiming Wang ${ }^{1}$ \\ ${ }^{1}$ Department of Internal Medicine, Henan Cancer Hospital Affiliated to Zhengzhou University, Zhengzhou, China; ${ }^{2}$ Department of Pharmacy, \\ Henan Cancer Hospital Affiliated to Zhengzhou University, Zhengzhou, China; ${ }^{3}$ School of Chinese Medicine of Hong Kong Baptist University, \\ Hong Kong, China; ${ }^{4}$ Department of Urology, Affiliated Cancer Hospital to Zhengzhou University, Henan Cancer Hospital, Zhengzhou, China; \\ ${ }^{5}$ Department of Pathology \& Laboratory Medicine, University of Wisconsin Carbone Cancer Center, Madison, WI, USA; ${ }^{6}$ Division of Surgical \\ Oncology, The Ohio State University Comprehensive Cancer Center, Columbus, OH, USA; ${ }^{7}$ Division of Hematology/Oncology, The Warren \\ Alpert Medical School of Brown University, Lifespan Cancer Institute, Rhode Island Hospital, Providence, RI, USA \\ Contributions: (I) Conception and design: Q Wang, X Wu, Y Ma; (II) Administrative support: None; (III) Provision of study materials or patients: Y \\ Wu, J Han; (IV) Collection and assembly of data: B Dong, D Li, Y Ma; (V) Data analysis and interpretation: B Dong, D Li, X Wu; (VI) Manuscript \\ writing: All authors; (VII) Final approval of manuscript: All authors. \\ "These authors contributed equally to this work. \\ Correspondence to: Qiming Wang, MD, PhD. Department of Internal Medicine, Henan Cancer Hospital Affiliated to Zhengzhou University, 127 \\ Dong Ming Road, Zhengzhou 450008, China. Email: qimingwang1006@126.com.
}

Background: Gastric cancer is the fifth most common type of cancer globally. We aimed to evaluate the reporting quality of clinical practice guidelines in the field of gastric cancer.

Methods: We searched Medline (via PubMed), China Biology Medicine, Chinese National Knowledge Infrastructure and WanFang databases and the websites of the main guideline development organizations from 2018 to 2020 for guidelines on gastric cancer. Data were extracted and the reporting quality evaluated by two researchers independently using the Reporting Items for Practice Guidelines in Healthcare (RIGHT) checklist. We assessed the compliance of the guidelines to each of the 35 items of RIGHT and summarized the reporting proportions of the seven domains of RIGHT.

Results: Eighteen guidelines were included. The mean proportion of appropriately reported RIGHT items was $52.4 \%$. Among the seven domains of the RIGHT checklist, Basic information had the highest reporting rate $(78.7 \%)$, and Review and quality assurance domain the lowest rate (16.7\%). The domains Evidence (40.0\%), Funding and declaration and management of interests (43.1\%), and Other information (31.5\%) had also reporting rates below 50\%. Two RIGHT items (17 and 19b) were not reported by any of the guidelines. Conclusions: The reporting quality of gastric cancer guidelines published in the years 2018-2020 was suboptimal, especially regarding the reporting of review, quality assurance and evidence. Guideline developers should pay attention on rigorous reporting following international standard to improve the quality of guidelines.

Keywords: Gastric cancer; Reporting Items for Practice Guidelines in Healthcare (RIGHT); practice guideline; reporting quality

Submitted Mar 16, 2021. Accepted for publication Jun 02, 2021.

doi: 10.21037/atm-21-2491

View this article at: http://dx.doi.org/10.21037/atm-21-2491 


\section{Introduction}

Gastric cancer is the fifth most frequently diagnosed cancer and the third leading cause of cancer-related deaths in the world $(1,2)$. As a result, gastric cancer presents a serious threat to global health. The incidence of gastric cancer varies greatly across the world, being highest in East Asia, South and Central America and Eastern Europe (3). In China, gastric cancer is one of the leading causes of cancer-related mortality (4). In contrast, the incidence of gastric cancer in Western Europe and North America has decreased over the past decades and is no longer among the most common cancer types, but still is a leading cause of cancer death $(5,6)$.

The main risk factors of gastric cancer include Helicobacter pylori (HP) infection, smoking, high salt diets, and susceptibility to hereditary gastric cancer syndrome (7-9). The etiology, epidemiological characteristics, primary tumor site, histopathology, treatment strategies, prognoses, molecular biological characteristics, and immunological characteristics differ between gastric cancer patients in Western countries and Asia. In East Asia, gastric cancer is often diagnosed in its early stages in some countries like Japan and South Korea largely due to screening efforts, but in China more than $80 \%$ of gastric cancer patients are already in advanced stages at the time of diagnosis (10). Therefore, the treatment practices differ between regions, and clinical practice guidelines for the management of gastric cancer have been drawn up in different countries to optimize patient care in the local context (11-16).

Clinical practice guidelines are collections of clinical recommendations based on systematic evaluation of evidence that balances the advantages and disadvantages of different treatment options. Guidelines form an important tool to standardize the treatment behavior of clinicians, enhance the quality of medical care, and reduce costs $(17,18)$. Guidelines are conducive to a reasonable use of medical resources and the protection of patients' rights and interests (19). The formulation of a guideline is affected by many factors, and clear, transparent, and precise reporting is one of the important factors that determine the effective promotion and implementation of the guideline. However, to our knowledge, the quality of guidelines for gastric cancer has not been adequately assessed. AGREE II and Reporting Items for Practice Guidelines in Healthcare (RIGHT) are commonly used to evaluate the reporting quality and limitations of guidelines (20-22). RIGHT has been widely recognized as a standard for reporting criteria for guidelines $(23,24)$. The purpose of this study was to evaluate the reporting quality of guidelines on gastric cancer using the RIGHT checklist and provide suggestions for the development of future guidelines.

\section{Methods}

\section{Literature search}

We searched Medline (via PubMed), China Biology Medicine (CBM), Chinese National Knowledge Infrastructure (CNKI) and WanFang databases, and the websites of guideline development organizations including National Comprehensive Cancer Network (NCCN), Guidelines International Network (GIN), National Institute for Health and Care Excellence (NICE) and World Health Organization (WHO) from January 1, 2018 to December 1, 2020 to identify clinical practice guidelines for gastric cancer. The complete search strategy is shown in Supplementary Appendix 1.

\section{Inclusion and exclusion criteria}

We included clinical practice guidelines for gastric cancer. The following types of guidelines were excluded: (I) guidelines published in languages other than English or Chinese; (II) translations, summaries, and interpretations of guidelines; (III) older versions of guidelines if an updated version was available; and (IV) guidelines that included recommendations for tumors other than gastric cancer.

\section{Guideline selection and data extraction}

Two investigators independently screened first the titles and abstracts of the identified records, and then the full texts of potentially relevant articles to determine if the articles met the inclusion criteria of this study. They then extracted the data from the retrieved guidelines independently using a standardized data collection form. Disagreements were resolved through consensus. Extracted data included title, scope and purpose, publication year, publication format, developer organization, country or region of development, development method (evidence-based or not), and funding.

\section{Reporting quality evaluation of guidelines}

We used the RIGHT checklist to evaluate reporting quality of the eligible guidelines. The RIGHT list contains 35 items categorized into the following seven 


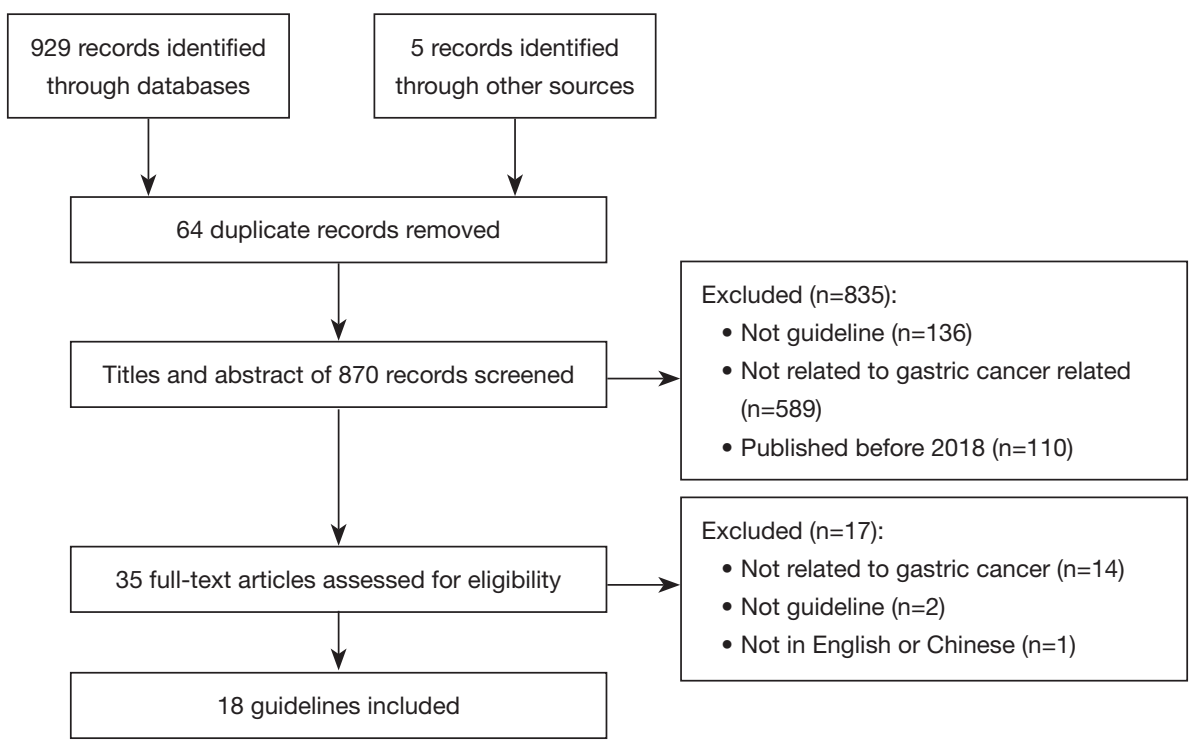

Figure 1 Flowchart of systematic search.

domains: "Basic information", "Background", "Evidence", "Recommendations", "Review and quality assurance", "Funding and declaration and management of interests", and "Other information" (23). Two researchers independently assessed the quality of each eligible guideline. Disagreements between the investigators were resolved through consensus or consulting an independent expert adjudicator. The items were evaluated as "Reported" (relevant information was fully reported), "Not Reported" (relevant information was lacking), or "Partially Reported" if some but not all aspects were reported. If an item did not apply for evaluation in a particular guideline, we rated it as "Not applicable".

\section{Data synthesis and analysis}

We summarized the basic characteristics of all included guidelines. We calculated for each guideline the number of items reported. We calculated the mean reporting rates of each item, of each domain, and the overall reporting compliance rate, over all guidelines. When calculating the domain and overall rates, each sub-item was weighted equally, and items rated as "partially reported" were considered as not having been reported. We compared the reporting rates of guidelines published in years 2018, 2019 and 2020 using analysis of variance (ANOVA).

\section{Statistical analysis}

All analyses were performed using SPSS V.26.0 and Office
Excel 2019, which was used to calculate the reporting rates of the RIGHT items and domains for CPGs. The groups were compared by a one-way analysis of variance (ANOVA). $\mathrm{P}<0.05$ was considered statistically significant.

\section{Results}

\section{Guideline characteristics}

Our initial search revealed 934 articles (929 from literature databases, five from websites of guideline development organizations). After screening titles and abstracts and reviewing the full texts of potentially relevant articles, 18 guidelines were eventually included (Figure 1). Seventeen guidelines were developed by medical specialty associations, and one by a multidisciplinary panel. Five guidelines were developed in European countries, five in Japan, and four in China. In addition, one guideline from the United States, South Korea, New Zealand and Brazil each was included. The characteristics of the included guidelines are presented in Table 1.

\section{Reporting quality of the included guidelines}

The number of reported RIGHT checklist items ranged from $10(31.4 \%)$ to $31(88.6 \%)$, with a mean of 18.3 (52.4\%) among the included guidelines (Figure 2). In eight guidelines, less than one-half of the items were reported. We found that guidelines published in 2018 seemed to have 


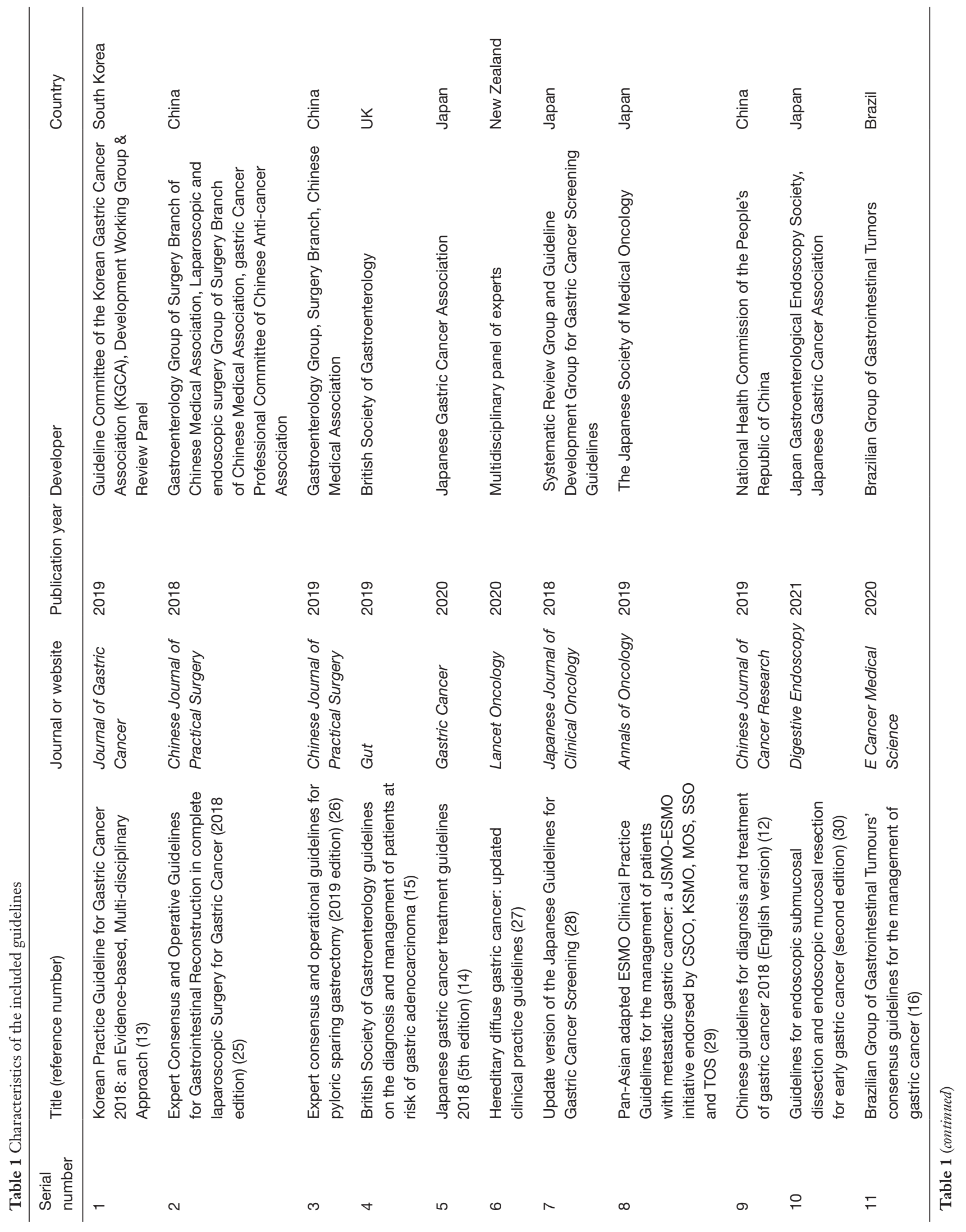




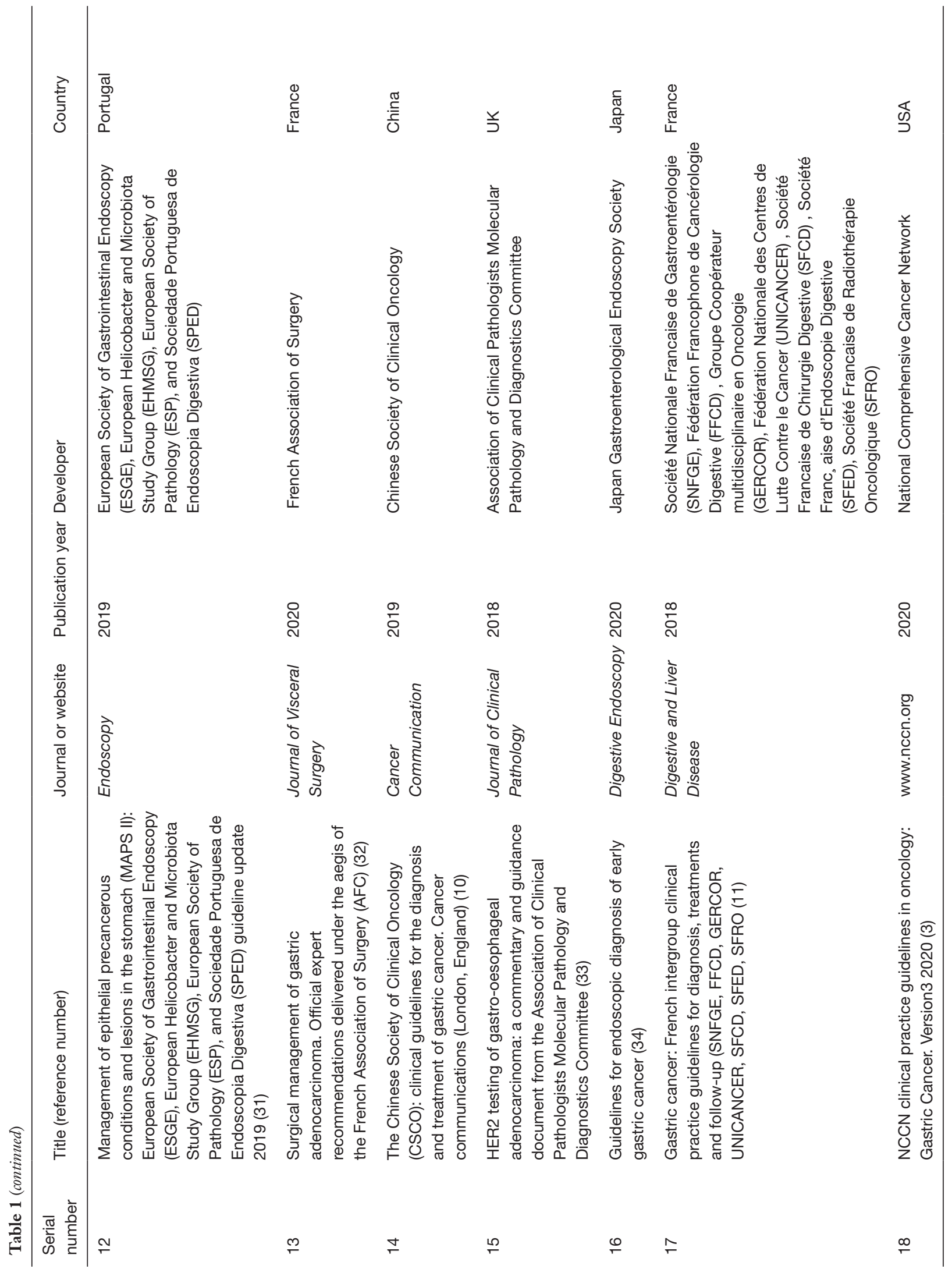




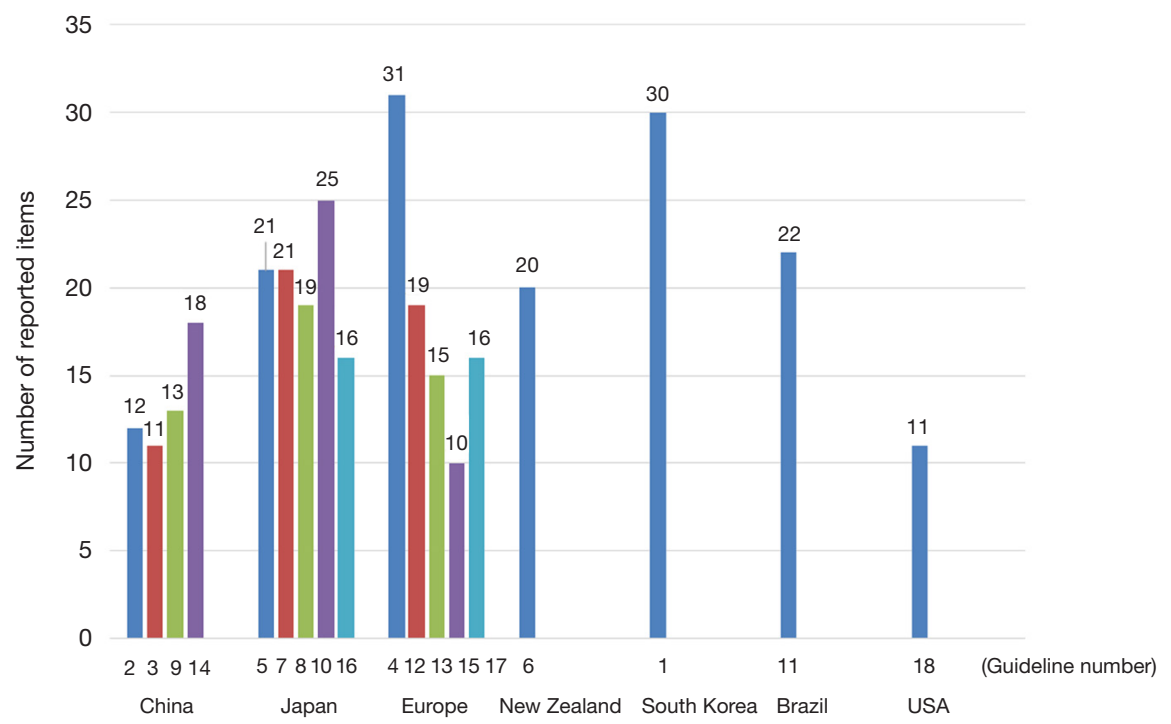

Figure 2 The number of reported RIGHT checklist items in each included guideline, grouped by region of development (serial numbers refer to Table 1).

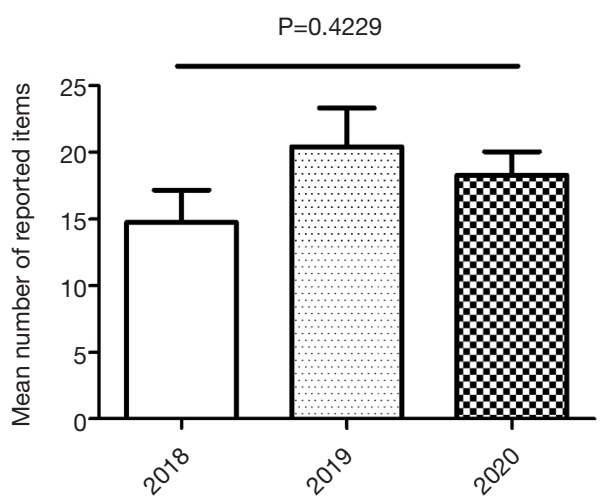

Figure 3 The mean number of reported items with $95 \%$ confidence interval in the included guidelines grouped by year of publication.

lower reporting quality, but there was no difference in the reporting rates between guidelines published in 2018, 2019 and 2020 ( $\mathrm{P}=0.42$, Figure 3). The three guidelines with the highest reporting quality were from the United Kingdom, South Korea and Japan, (Figure 2).

The reporting proportions of the seven RIGHT domains were $78.7 \%$ (Basic information), 63.2\% (Background), 40.0\% (Evidence), $64.3 \% \%$ (Recommendations), $16.7 \%$ (Review and quality assurance), $43.1 \% \%$ (Funding and declaration and management of interests), and 31.5\% (Other information). The most frequently reported items of the
RIGHT checklist were items 1a ("Be able to judge by the title as a guide"), 7a ("Describe the main target population of the guidelines") and 13a ("Provide clear, precise, and actionable recommendations") which all 18 guidelines complied with. These were followed by item 4 ("Identify at least one corresponding author"), which was reported in 17 (94.4\%) guidelines. None of the guidelines reported item 17 ("Describe whether the guidance has been subjected to a quality control procedure") or item 19b (" Describe how should conflicts of interest be evaluated and managed and how should users be guided to obtain these statements"). Only one guideline reported item 22 ("Describe any limitations in the guideline development process [such as the development groups were not multidisciplinary, or patients' values and preferences were not sought) and indicate how these limitations might have affected the validity of the recommendations"). The reporting proportions of items $8 \mathrm{a}, 8 \mathrm{~b}, 11 \mathrm{a}, 11 \mathrm{~b}$ and $18 \mathrm{~b}$ were also less than $30 \%$ (Table 2).

\section{Discussion}

We evaluated 18 guidelines on gastric cancer and found that eight of complied with less than half of the RIGHT checklist items, indicating low reporting quality. Items related to guideline identification, recommendations, description of the focus and the primary population or other basic contents were mostly well reported. However, 
Table 2 Compliance to the RIGHT checklist items by the included guidelines.

\begin{tabular}{|c|c|c|c|c|c|c|c|c|c|c|c|c|c|c|c|c|c|c|c|c|}
\hline \multirow{2}{*}{ Domain } & \multirow{2}{*}{ Item } & \multicolumn{18}{|c|}{ Guidelines (serial number) } & \multirow{2}{*}{$\begin{array}{c}\text { Reporting } \\
\text { proportion (\%) }\end{array}$} \\
\hline & & 1 & 2 & 3 & 4 & 5 & 6 & 7 & 8 & 9 & 10 & 11 & 12 & 13 & 14 & 15 & 16 & 17 & 18 & \\
\hline \multirow[t]{6}{*}{ Basic information } & $1 \mathrm{a}$ & Y & Y & Y & $\mathrm{Y}$ & $\mathrm{Y}$ & $\mathrm{Y}$ & Y & Y & Y & $\mathrm{Y}$ & $\mathrm{Y}$ & $\mathrm{Y}$ & $\mathrm{Y}$ & $\mathrm{Y}$ & $\mathrm{Y}$ & Y & Y & $\mathrm{Y}$ & 100.0 \\
\hline & $1 b$ & $Y$ & $Y$ & $\mathrm{Y}$ & $\mathrm{N}$ & $\mathrm{Y}$ & $\mathrm{N}$ & $\mathrm{N}$ & $\mathrm{N}$ & $Y$ & $\mathrm{~N}$ & $N$ & $\mathrm{Y}$ & $\mathrm{N}$ & $\mathrm{N}$ & $\mathrm{N}$ & $\mathrm{N}$ & $N$ & $\mathrm{Y}$ & 38.9 \\
\hline & $1 c$ & $\mathrm{~N}$ & $\mathrm{Y}$ & $\mathrm{Y}$ & $\mathrm{Y}$ & $\mathrm{Y}$ & $\mathrm{N}$ & $\mathrm{Y}$ & $\mathrm{Y}$ & Y & Y & Y & $\mathrm{Y}$ & $\mathrm{Y}$ & $\mathrm{Y}$ & $\mathrm{Y}$ & Y & Y & $\mathrm{Y}$ & 88.9 \\
\hline & 2 & $Y$ & $\mathrm{~N}$ & $\mathrm{~N}$ & $\mathrm{Y}$ & $\mathrm{Y}$ & $\mathrm{Y}$ & $Y$ & $Y$ & $\mathrm{~N}$ & $\mathrm{~N}$ & $N$ & $Y$ & $\mathrm{~N}$ & $Y$ & $\mathrm{~N}$ & $Y$ & $Y$ & $Y$ & 61.1 \\
\hline & 3 & $Y$ & $\mathrm{Y}$ & $Y$ & $\mathrm{Y}$ & $\mathrm{Y}$ & $\mathrm{Y}$ & $\mathrm{N}$ & $Y$ & $\mathrm{Y}$ & $Y$ & $Y$ & $\mathrm{Y}$ & $\mathrm{N}$ & $Y$ & $\mathrm{Y}$ & $Y$ & $Y$ & $Y$ & 88.9 \\
\hline & 4 & $\mathrm{Y}$ & $\mathrm{Y}$ & $Y$ & $\mathrm{Y}$ & $\mathrm{Y}$ & $\mathrm{Y}$ & $Y$ & $Y$ & $\mathrm{~N}$ & $Y$ & $Y$ & $\mathrm{Y}$ & $\mathrm{Y}$ & $Y$ & $\mathrm{Y}$ & $Y$ & $Y$ & $\mathrm{Y}$ & 94.4 \\
\hline Reporting proportion (\%) & & 83.3 & 83.3 & 83.3 & 83.3 & 100.0 & 66.7 & 66.7 & 83.3 & 66.7 & 66.7 & 66.7 & 100.0 & 50.0 & 83.3 & 66.7 & 83.3 & 83.3 & 100 & 78.7 \\
\hline \multirow[t]{8}{*}{ Background } & 5 & Y & $\mathrm{N}$ & $\mathrm{Y}$ & $\mathrm{Y}$ & $\mathrm{N}$ & $\mathrm{Y}$ & Y & Y & $\mathrm{Y}$ & $\mathrm{N}$ & $\mathrm{Y}$ & $\mathrm{Y}$ & $\mathrm{Y}$ & $\mathrm{Y}$ & $\mathrm{N}$ & $\mathrm{Y}$ & $\mathrm{Y}$ & $\mathrm{Y}$ & 77.8 \\
\hline & 6 & $\mathrm{Y}$ & Y & $\mathrm{Y}$ & $\mathrm{Y}$ & $\mathrm{N}$ & $\mathrm{Y}$ & $\mathrm{Y}$ & Y & $\mathrm{Y}$ & $\mathrm{Y}$ & $\mathrm{Y}$ & $\mathrm{Y}$ & $\mathrm{N}$ & $\mathrm{Y}$ & $\mathrm{N}$ & $\mathrm{Y}$ & $\mathrm{Y}$ & $\mathrm{Y}$ & 83.3 \\
\hline & $7 a$ & Y & Y & $\mathrm{Y}$ & $\mathrm{Y}$ & $\mathrm{Y}$ & $\mathrm{Y}$ & $\mathrm{Y}$ & $Y$ & $Y$ & $Y$ & $Y$ & $Y$ & $Y$ & $Y$ & $Y$ & $Y$ & $Y$ & $Y$ & 100.0 \\
\hline & $7 b$ & Y & $\mathrm{N}$ & $\mathrm{N}$ & $\mathrm{Y}$ & Y & $\mathrm{N}$ & $\mathrm{N}$ & $Y$ & $Y$ & $Y$ & $Y$ & $Y$ & $\mathrm{~N}$ & $Y$ & $\mathrm{~N}$ & $\mathrm{~N}$ & $Y$ & $Y$ & 61.1 \\
\hline & $8 a$ & $Y$ & $Y$ & $\mathrm{~N}$ & $Y$ & $\mathrm{~N}$ & $\mathrm{~N}$ & $\mathrm{~N}$ & $N$ & $\mathrm{~N}$ & $\mathrm{~N}$ & $N$ & $\mathrm{~N}$ & $\mathrm{~N}$ & $\mathrm{~N}$ & $\mathrm{~N}$ & $\mathrm{~N}$ & $\mathrm{~N}$ & $\mathrm{~N}$ & 16.7 \\
\hline & $8 b$ & Y & Y & $\mathrm{Y}$ & $\mathrm{Y}$ & $\mathrm{N}$ & $\mathrm{N}$ & $\mathrm{N}$ & $\mathrm{N}$ & $\mathrm{N}$ & $\mathrm{N}$ & $\mathrm{N}$ & $\mathrm{N}$ & $\mathrm{N}$ & $\mathrm{N}$ & $\mathrm{N}$ & $\mathrm{N}$ & $\mathrm{N}$ & $\mathrm{N}$ & 22.2 \\
\hline & $9 a$ & $Y$ & $\mathrm{~N}$ & $\mathrm{~N}$ & $Y$ & $\mathrm{~N}$ & $Y$ & $Y$ & $Y$ & $\mathrm{~N}$ & $Y$ & $Y$ & $\mathrm{~N}$ & $\mathrm{~N}$ & $\mathrm{~N}$ & $\mathrm{~N}$ & $Y$ & $N$ & $Y$ & 50.0 \\
\hline & $9 b$ & $\mathrm{Y}$ & $\mathrm{N}$ & $\mathrm{N}$ & $\mathrm{Y}$ & $\mathrm{N}$ & Y & $\mathrm{N}$ & $Y$ & $\mathrm{~N}$ & $Y$ & $\mathrm{Y}$ & Y & $Y$ & $Y$ & $Y$ & $Y$ & $\mathrm{Y}$ & $Y$ & 66.7 \\
\hline Reporting proportion (\%) & & 100.0 & 50.0 & 50.0 & 100.0 & 25.0 & 62.5 & 50.0 & 75.0 & 50.0 & 62.5 & 75.0 & 62.5 & 37.5 & 62.5 & 75.0 & 62.5 & 62.5 & 75.0 & 63.2 \\
\hline \multirow[t]{5}{*}{ Evidence } & $10 a$ & $Y$ & $\mathrm{~N}$ & $\mathrm{Y}$ & $\mathrm{Y}$ & $\mathrm{N}$ & $\mathrm{Y}$ & $Y$ & $\mathrm{~N}$ & $\mathrm{~N}$ & $Y$ & $\mathrm{Y}$ & $\mathrm{N}$ & $\mathrm{Y}$ & $\mathrm{N}$ & $\mathrm{N}$ & $Y$ & $\mathrm{~N}$ & $\mathrm{~N}$ & 50.0 \\
\hline & $10 b$ & $Y$ & $\mathrm{~N}$ & $\mathrm{~N}$ & $Y$ & $\mathrm{~N}$ & $\mathrm{~N}$ & $Y$ & $Y$ & $\mathrm{~N}$ & $\mathrm{~N}$ & $Y$ & $\mathrm{~N}$ & $\mathrm{Y}$ & $\mathrm{N}$ & $\mathrm{N}$ & $Y$ & $\mathrm{~N}$ & $\mathrm{~N}$ & 38.9 \\
\hline & $11 a$ & $Y$ & $\mathrm{~N}$ & $\mathrm{~N}$ & $\mathrm{Y}$ & $\mathrm{N}$ & $\mathrm{N}$ & $Y$ & $N$ & $\mathrm{~N}$ & $\mathrm{~N}$ & $\mathrm{~N}$ & $\mathrm{~N}$ & $\mathrm{~N}$ & $\mathrm{~N}$ & $\mathrm{~N}$ & $\mathrm{~N}$ & $\mathrm{~N}$ & $\mathrm{Y}$ & 22.2 \\
\hline & $11 b$ & $Y$ & $\mathrm{~N}$ & $\mathrm{~N}$ & $\mathrm{~N}$ & $\mathrm{~N}$ & $\mathrm{~N}$ & $\mathrm{Y}$ & $\mathrm{N}$ & $\mathrm{N}$ & $\mathrm{N}$ & $N$ & $\mathrm{~N}$ & $\mathrm{~N}$ & $\mathrm{~N}$ & $\mathrm{~N}$ & $\mathrm{Y}$ & $N$ & $\mathrm{~N}$ & 16.7 \\
\hline & 12 & $\mathrm{Y}$ & $\mathrm{N}$ & $\mathrm{N}$ & $\mathrm{Y}$ & $\mathrm{N}$ & $\mathrm{Y}$ & $Y$ & $Y$ & $\mathrm{~N}$ & $\mathrm{Y}$ & $Y$ & $Y$ & $\mathrm{Y}$ & $\mathrm{Y}$ & $\mathrm{N}$ & $Y$ & $Y$ & $\mathrm{Y}$ & 72.2 \\
\hline Reporting proportion (\%) & & 100.0 & 0.0 & 20.0 & 80.0 & 0 & 40.0 & 100.0 & 40.0 & 0 & 40.0 & 60.0 & 20.0 & 60.0 & 20.0 & 0 & 80.0 & 20.0 & 40.0 & 40.0 \\
\hline \multirow[t]{7}{*}{ Recommendations } & $13 a$ & $\mathrm{Y}$ & $\mathrm{Y}$ & $\mathrm{Y}$ & $\mathrm{Y}$ & $\mathrm{Y}$ & $\mathrm{Y}$ & $\mathrm{Y}$ & $Y$ & $Y$ & $Y$ & $Y$ & $\mathrm{Y}$ & $\mathrm{Y}$ & $\mathrm{Y}$ & $\mathrm{Y}$ & $\mathrm{Y}$ & $\mathrm{Y}$ & $\mathrm{Y}$ & 100.0 \\
\hline & $13 b$ & Y & NA & NA & $\mathrm{Y}$ & $\mathrm{Y}$ & $\mathrm{Y}$ & $\mathrm{Y}$ & $\mathrm{Y}$ & $\mathrm{Y}$ & Y & $\mathrm{Y}$ & $\mathrm{Y}$ & NA & $\mathrm{Y}$ & NA & $\mathrm{Y}$ & $\mathrm{Y}$ & $\mathrm{Y}$ & 77.8 \\
\hline & $13 c$ & $Y$ & NA & NA & $\mathrm{Y}$ & NA & $\mathrm{N}$ & $\mathrm{P}$ & Y & $\mathrm{N}$ & $\mathrm{Y}$ & $\mathrm{N}$ & $\mathrm{N}$ & Y & $\mathrm{Y}$ & $\mathrm{N}$ & Y & $Y$ & $\mathrm{Y}$ & 50.0 \\
\hline & $14 a$ & $\mathrm{Y}$ & $\mathrm{N}$ & $\mathrm{N}$ & $\mathrm{Y}$ & $\mathrm{Y}$ & $\mathrm{Y}$ & $\mathrm{N}$ & $\mathrm{Y}$ & $\mathrm{N}$ & $\mathrm{N}$ & $\mathrm{N}$ & $\mathrm{N}$ & $\mathrm{N}$ & $\mathrm{N}$ & $\mathrm{N}$ & Y & $\mathrm{N}$ & $\mathrm{Y}$ & 38.9 \\
\hline & $14 b$ & $\mathrm{Y}$ & $\mathrm{N}$ & $\mathrm{N}$ & $\mathrm{Y}$ & $\mathrm{N}$ & $\mathrm{Y}$ & $\mathrm{N}$ & Y & Y & Y & $Y$ & $\mathrm{Y}$ & $\mathrm{Y}$ & $\mathrm{N}$ & $\mathrm{N}$ & Y & $\mathrm{N}$ & $\mathrm{Y}$ & 61.1 \\
\hline & $14 c$ & Y & $\mathrm{Y}$ & $\mathrm{N}$ & $\mathrm{Y}$ & $\mathrm{Y}$ & $\mathrm{Y}$ & $\mathrm{N}$ & $\mathrm{N}$ & Y & $\mathrm{N}$ & Y & Y & $\mathrm{Y}$ & $\mathrm{Y}$ & $\mathrm{N}$ & $\mathrm{Y}$ & $\mathrm{N}$ & $\mathrm{Y}$ & 66.7 \\
\hline & 15 & Y & $\mathrm{N}$ & $\mathrm{N}$ & $\mathrm{Y}$ & $\mathrm{N}$ & $\mathrm{N}$ & Y & $\mathrm{Y}$ & $\mathrm{N}$ & $\mathrm{Y}$ & $\mathrm{Y}$ & $\mathrm{Y}$ & Y & $\mathrm{N}$ & $\mathrm{N}$ & $\mathrm{Y}$ & $\mathrm{N}$ & $\mathrm{Y}$ & 55.6 \\
\hline Reporting proportion (\%) & & 100.0 & 28.6 & 14.3 & 100.0 & 57.1 & 71.4 & 42.9 & 85.7 & 57.1 & 71.4 & 71.4 & 71.4 & 71.4 & 57.1 & 14.3 & 100.0 & 42.9 & 100.0 & 64.3 \\
\hline \multirow{2}{*}{$\begin{array}{l}\text { Review and quality } \\
\text { assurance }\end{array}$} & 16 & $\mathrm{Y}$ & $\mathrm{N}$ & $\mathrm{N}$ & $\mathrm{Y}$ & $\mathrm{N}$ & $\mathrm{N}$ & Y & $\mathrm{N}$ & $\mathrm{N}$ & $\mathrm{Y}$ & $\mathrm{N}$ & $\mathrm{N}$ & $\mathrm{N}$ & $\mathrm{N}$ & Y & $\mathrm{Y}$ & $\mathrm{N}$ & $\mathrm{N}$ & 33.3 \\
\hline & 17 & $\mathrm{~N}$ & $\mathrm{~N}$ & $\mathrm{~N}$ & $\mathrm{~N}$ & $\mathrm{~N}$ & $\mathrm{~N}$ & $\mathrm{~N}$ & $\mathrm{~N}$ & $\mathrm{~N}$ & $\mathrm{~N}$ & $\mathrm{~N}$ & $\mathrm{~N}$ & $\mathrm{~N}$ & $\mathrm{~N}$ & $\mathrm{~N}$ & $\mathrm{~N}$ & $\mathrm{~N}$ & $\mathrm{~N}$ & 0 \\
\hline Reporting proportion (\%) & & 50.0 & 0 & 0 & 50.0 & 0 & 0 & 50.0 & 0 & 0 & 50.0 & 0 & 0 & 0 & 0 & 50.0 & 50.0 & 0 & 0 & 16.7 \\
\hline
\end{tabular}

Table 2 (continued) 
Table 2 (continued)

\begin{tabular}{|c|c|c|c|c|c|c|c|c|c|c|c|c|c|c|c|c|c|c|c|c|}
\hline \multirow{2}{*}{ Domain } & \multirow{2}{*}{ Item- } & \multicolumn{18}{|c|}{ Guidelines (serial number) } & \multirow{2}{*}{$\begin{array}{c}\text { Reporting } \\
\text { proportion (\%) }\end{array}$} \\
\hline & & 1 & 2 & 3 & 4 & 5 & 6 & 7 & 8 & 9 & 10 & 11 & 12 & 13 & 14 & 15 & 16 & 17 & 18 & \\
\hline \multirow{4}{*}{$\begin{array}{l}\text { Funding and declaration } \\
\text { and management of } \\
\text { interests }\end{array}$} & $18 a$ & $\mathrm{Y}$ & $\mathrm{N}$ & $\mathrm{N}$ & $\mathrm{Y}$ & $\mathrm{Y}$ & $\mathrm{Y}$ & Y & $\mathrm{Y}$ & $\mathrm{N}$ & Y & Y & $\mathrm{N}$ & $\mathrm{N}$ & Y & $\mathrm{Y}$ & $\mathrm{Y}$ & $\mathrm{N}$ & $\mathrm{N}$ & 61.1 \\
\hline & $18 b$ & Y & $\mathrm{N}$ & $\mathrm{N}$ & $\mathrm{Y}$ & $\mathrm{N}$ & $\mathrm{N}$ & $\mathrm{Y}$ & $\mathrm{N}$ & $\mathrm{N}$ & $\mathrm{N}$ & Y & $\mathrm{N}$ & $\mathrm{N}$ & $\mathrm{Y}$ & $\mathrm{N}$ & $\mathrm{N}$ & $\mathrm{N}$ & $\mathrm{N}$ & 27.8 \\
\hline & $19 a$ & Y & $\mathrm{N}$ & $\mathrm{N}$ & $\mathrm{Y}$ & $\mathrm{Y}$ & $\mathrm{Y}$ & $\mathrm{Y}$ & Y & $\mathrm{N}$ & Y & $\mathrm{Y}$ & $\mathrm{Y}$ & $\mathrm{Y}$ & $\mathrm{Y}$ & $\mathrm{Y}$ & $\mathrm{Y}$ & $\mathrm{Y}$ & $\mathrm{Y}$ & 83.3 \\
\hline & $19 b$ & $\mathrm{~N}$ & $\mathrm{~N}$ & $\mathrm{~N}$ & $\mathrm{~N}$ & $\mathrm{~N}$ & $\mathrm{~N}$ & $\mathrm{~N}$ & $\mathrm{~N}$ & $\mathrm{~N}$ & $\mathrm{~N}$ & $\mathrm{~N}$ & $\mathrm{~N}$ & $\mathrm{~N}$ & $\mathrm{~N}$ & $\mathrm{~N}$ & $\mathrm{~N}$ & $\mathrm{~N}$ & $\mathrm{~N}$ & 0 \\
\hline Reporting proportion (\%) & & 75.0 & 0 & 0 & 75.0 & 50.0 & 50.0 & 75.0 & 50.0 & 0 & 50.0 & 75.0 & 25.0 & 25.0 & 75.0 & 50.0 & 50.0 & 25.0 & 25.0 & 43.1 \\
\hline \multirow[t]{3}{*}{ Other information } & 20 & $\mathrm{Y}$ & $\mathrm{N}$ & $\mathrm{N}$ & $\mathrm{Y}$ & $\mathrm{Y}$ & $\mathrm{Y}$ & $\mathrm{N}$ & $\mathrm{N}$ & Y & $\mathrm{N}$ & $\mathrm{Y}$ & $\mathrm{Y}$ & $\mathrm{N}$ & $\mathrm{N}$ & $\mathrm{N}$ & $\mathrm{N}$ & $\mathrm{Y}$ & $\mathrm{Y}$ & 50.0 \\
\hline & 21 & $\mathrm{~N}$ & $\mathrm{Y}$ & $\mathrm{N}$ & $\mathrm{Y}$ & $\mathrm{Y}$ & $\mathrm{Y}$ & $\mathrm{Y}$ & $\mathrm{N}$ & $\mathrm{N}$ & $\mathrm{N}$ & $\mathrm{N}$ & $\mathrm{N}$ & $\mathrm{N}$ & $\mathrm{N}$ & $\mathrm{N}$ & $\mathrm{Y}$ & $\mathrm{N}$ & $\mathrm{Y}$ & 38.9 \\
\hline & 22 & $\mathrm{~N}$ & $\mathrm{~N}$ & $\mathrm{~N}$ & $\mathrm{Y}$ & $\mathrm{N}$ & $\mathrm{N}$ & $\mathrm{N}$ & $\mathrm{N}$ & $\mathrm{N}$ & $\mathrm{N}$ & $\mathrm{N}$ & $\mathrm{N}$ & $\mathrm{N}$ & $\mathrm{N}$ & $\mathrm{N}$ & $\mathrm{N}$ & $\mathrm{N}$ & $\mathrm{N}$ & 5.6 \\
\hline Reporting proportion (\%) & & 33.3 & 33.3 & 0 & 100.0 & 66.7 & 66.7 & 33.3 & 0 & 33.3 & 0 & 33.3 & 33.3 & 0 & 0 & 0 & 33.3 & 33.3 & 66.7 & 31.5 \\
\hline $\begin{array}{l}\text { Total reporting } \\
\text { proportion (\%) }\end{array}$ & & 85.7 & 34.3 & 31.4 & 88.6 & 45.7 & 57.1 & 60.0 & 60.0 & 37.1 & 54.3 & 62.9 & 54.3 & 42.9 & 51.4 & 28.6 & 71.4 & 45.7 & 31.4 & \\
\hline
\end{tabular}

Y, reported; N, not reported; NA, not applicable; P, partially reported. Serial numbers of the guidelines refer to Table 1. The description of each item can be found in the RIGHT checklist (23).

quality assurance, evaluation and management of conflicts of interest, limitations of the guideline, information on the systematic reviews on which the guidance is based, and the intended primary users or the target settings were insufficiently reported. Similar results have been found for guidelines on other topics as well $(17,35)$.

High quality guidelines are especially important in gastric cancer for several reasons; First, the incidence rates of gastric cancer vary significantly throughout the world leading to significant variation in patients care. Second, stage migration, surgical techniques and supportive care have led to further disparities in patient management and outcomes. Third, interpreting clinical trials in gastric cancer is specially challenging depending on the geographic distribution of the population enrolled and the era when the trials were conducted.

Taken together, a high-quality guideline is important in this setting to guide practitioners worldwide. Given the heterogeneity of disease presentations and the complexity of therapeutic decisions, the development and implementation of guidelines should be a detailed and rigorous process where several interdisciplinary teams of experts are involved. High quality guidelines can eliminate inappropriate interventions, improve transparency of costs, and reduce health-care expenses, while low quality guidelines will be hard to interpret and implement and eventually lead to worse outcome.

Among the seven domains of the RIGHT checklist, the domain "basic information" was reported better than other domains. However, 11 guidelines did not indicate the year of publication in the title, and seven guidelines did not present a summary of the recommendations. Presenting the publication year in the title and a concise summary of the recommendations can help the users obtain key information quickly by taking a glance at the title or summary, and therefore improve the efficiency of reading and the dissemination of the guideline. Therefore, it is important to pay more attention on strengthening the reporting of these basic information items.

The reporting proportion in the domain "Review and quality assurance" was lowest among all seven domains. None of the guidelines described whether the guidance had been subject to a quality control procedure, and only six guidelines indicated whether the draft guideline underwent independent review. The details of the reviewers, reviewing process and feedback process were also rarely reported. The independent review and quality control procedures of the guidelines are meaningful for improving the quality and credibility of the guidelines and can support the wide promotion and application of the guidelines. This domain needs more focus from guideline developers in the future.

In the domain "Evidence", the overall reporting proportion was $40 \%$, but the information on the systematic reviews on which the guidance was based (items 11a and 11b) was reported much less frequently. This result is consistent with several other studies that used AGREEII to evaluate 
the methodological quality of guidelines (36-38). The item $11 \mathrm{~b}$ contains multiple aspects: whether existing systematic reviews were used, or new ones conducted, the search strategies and the selection criteria, evaluation of the risk of bias, and updating the reviews. Researchers may find this RIGHT item inconvenient to respond to since it covers multiple factors. The RIGHT Working Group has planned to expand the checklist with additional and more specific items related to systematic reviews (39). This improvement will increase the convenience and operability of the RIGHT checklist. The evidence from systematic reviews is the basis for forming recommendations in the guidelines and improving the quality of reporting the sources of the evidence is critical to the quality of the content of the guidelines.

The integrity of the guidelines depends on the process used to minimize bias of its committee members. Guideline developers must submit to continuous reviews of any potential conflict of interests. Avoiding panelists with COI might not be an option when recruiting academic physicians to draft the guidelines, however, panelists should disclose and identify factors that may mitigate the likelihood of conflicts of interest. Implementing effective management strategies to minimize the effects of COI is a key Commitment of the guideline committee to maintain and update explicit, transparent policies and procedures is very important to ensure the intended audience's trust.

In our evaluation, none of the guidelines described how conflicts of interest be evaluated and managed, and only five guidelines reported the role of the funders in the guideline development. This finding is consistent with other studies evaluating the reporting quality of guidelines $(17,40)$. In view of the important role of funding in the promotion of the guidelines, the guideline developers should strengthen the reporting of funding declaration and management of interest.

Seven guidelines described the suggestions for future research, and only one guideline reported the limitations in the guideline development process. Suggestions for further research can help to determine the direction of future studies (41), and reporting the limitations helps the guideline reader transparently evaluate the reliability and applicability of the recommendations (42). Both aspects are therefore important for increasing the credibility of the guideline.

To improve the quality of gastric cancer guidelines, the process should involve, not only development, but also validation. It should involve recognized key opinion leaders in the field who will provide a formal review of the literature and evaluate the strength and weaknesses of the evidence based on standardized criteria. It is imperative to define the outcome measures beyond survival and disease recurrence (i.e., quality of life, supportive care, cost effectiveness, etc.). Given the epidemiological variation in gastric cancer, an international collaboration between the east and the west on more global and country specific guidelines should be considered.

\section{Limitations}

We acknowledge that our study has some limitations. First, we only included guidelines published in English or Chinese. Consequently, we acknowledge that the results of this study are not necessarily generalizable to all guidelines on gastric cancer published worldwide. Second, RIGHT checklist is primarily intended for standardizing the development of guidelines, and as an evaluation tool.

\section{Questions to be further discussed and considered}

Question 1: What impact do you think the low reporting quality of clinical practice guidelines on gastric cancer will have on clinicians and clinical practices?

\section{Expert opinion: Dr. Kristina A. Matkowskyj}

Low reporting quality of clinical practice guidelines on gastric cancer can impact clinicians in multiple ways. Depending on the guideline used and the data/ information missing, it may not be apparent that the document represents a guideline, may not adequately address the patient population, lacks supporting data and recommendations, or have a multidisciplinary approach to care. As a result, this could result in less-than-optimal patient selection, staging, treatment and overall outcomes.

\section{Expert opinion: Dr. Aslam Ejaz}

I believe that low reporting quality will have some tangible effect on clinicians and clinical practices. I think this will be most relevant if all clinical practice guidelines were objectively evaluated and rated as low/medium/high. This would then give clinicians another metric to "choose" which guidelines to follow.

\section{Expert opinion: Dr. Khaldoun Almbanna}

High quality guidelines can eliminate inappropriate interventions, improve transparency of costs, and reduce health-care expenses, while low quality guidelines will be hard to interpret and implement and eventually lead to 
worse outcome.

Question 2: What do you think the most important aspects needed for developing high-quality clinical practice guidelines on gastric cancer are? Expert opinion: Dr. Kristina A. Matkowskyj

The most important aspect for developing high-quality clinical practice guidelines is a multidisciplinary team approach with consistent review of the literature and updating of the guidelines.

Expert opinion: Dr. Aslam Ejaz

To me, the most important aspect of developing highquality clinical practice guidelines on gastric cancer are a systematic process with a multi-disciplinary team. I also think that public reporting of the quality measures related to the development of such guidelines is also important. By being transparent and publicizing this, medical specialty associations will be forced to adhere to these guidelines as it will serve as a benchmark and allow for uniform evidencedbased practice for patients with gastric cancer.

\section{Expert opinion: Dr. Khaldoun Almbanna}

To improve the quality of gastric cancer guidelines, the process should involve, not only development, but also validation. It should involve recognized key opinion leaders in the field who will provide a formal review of the literature and evaluate the strength and weaknesses of the evidence based on standardized criteria. It is imperative to define the outcome measures beyond survival and disease recurrence (i.e., quality of life, supportive care, cost effectiveness, etc.). Given the epidemiological variation in gastric cancer, an international collaboration between the east and the west on more global and country specific guidelines should be considered.

Question 3: How do you think conflicts of interest in the guidelines should be handled? Expert opinion: Dr. Kristina A. Matkowskyj

Disclosure of all potential conflicts of interest should be required for all individuals prior to selection on the guideline committee. Rules should be established for what constitutes a true conflict and those members would not be permitted to serve on the committee. Conflict of interest forms should be updated at least twice per year for guideline committee members.

\section{Expert opinion: Dr. Aslam Ejaz}

Conflicts of interests for each author should be stated explicitly in the beginning of the guidelines.

Expert opinion: Dr. Khaldoun Almbanna
Panelists should disclose and identify factors that may mitigate the likelihood of conflicts of interest. Implementing effective management strategies to minimize the effects of COI is a key.

Commitment of the guideline committee to maintain and update explicit, transparent policies and procedures is very important to ensure the intended audience's trust.

\section{Conclusions}

The reporting quality of gastric cancer guidelines published between 2018 and 2020 was suboptimal, especially in the fields of review, quality assurance, and evidence. Therefore, we encourage guideline developers to follow rigorous reporting methodology and international standard to improve the quality. Consistent use of tools such as the RIGHT checklist (43) in guideline development has great potential to improve the reporting quality of guidelines.

\section{Acknowledgements}

The authors appreciate the academic support from the AME Reporting Guideline Collaborative Group.

Funding: This work was supported by the Medical science and Technology research project of Henan Province [No. LHGJ20190640 and 20190676], Health science and Technology Innovation Outstanding Young Talent Training Program of Henan Province [No. YXKC2020046], Henan Provincial Science and Technology Research Project (202102310157).

\section{Footnote}

Conflicts of Interest: All authors have completed the ICMJE uniform disclosure form (available at http://dx.doi. org/10.21037/atm-21-2491). KA received advisory boards and consulting fees from Merck, and lectures fees from Eisai, outside the submitted work. The other authors have no conflicts of interest to declare.

Ethical Statement: The authors are accountable for all aspects of the work in ensuring that questions related to the accuracy or integrity of any part of the work are appropriately investigated and resolved.

Open Access Statement: This is an Open Access article distributed in accordance with the Creative Commons Attribution-NonCommercial-NoDerivs 4.0 International 
License (CC BY-NC-ND 4.0), which permits the noncommercial replication and distribution of the article with the strict proviso that no changes or edits are made and the original work is properly cited (including links to both the formal publication through the relevant DOI and the license). See: https://creativecommons.org/licenses/by-nc-nd/4.0/.

\section{References}

1. Smyth EC, Nilsson M, Grabsch HI, et al. Gastric cancer. Lancet 2020;396:635-48.

2. Bray F, Ferlay J, Soerjomataram I, et al. Global cancer statistics 2018: GLOBOCAN estimates of incidence and mortality worldwide for 36 cancers in 185 countries. CA Cancer J Clin 2018;68:394-424. Erratum in: CA Cancer J Clin 2020;70:313.

3. NCCN. Gastric cancer Version 3.2020. Available online: www.nccnorg. 2020.

4. Nie $\mathrm{Y}, \mathrm{Wu} \mathrm{K}, \mathrm{Yu}$ J, et al. A global burden of gastric cancer: the major impact of China. Expert Rev Gastroenterol Hepatol 2017;11:651-61.

5. GBD 2017 Stomach Cancer Collaborators. The global, regional, and national burden of stomach cancer in 195 countries, 1990-2017: a systematic analysis for the Global Burden of Disease study 2017. Lancet Gastroenterol Hepatol 2020;5:42-54. Erratum in: Lancet Gastroenterol Hepatol 2020;5:e2.

6. Torre LA, Siegel RL, Ward EM, et al. Global Cancer Incidence and Mortality Rates and Trends--An Update. Cancer Epidemiol Biomarkers Prev 2016;25:16-27.

7. Hu B, El Hajj N, Sittler S, et al. Gastric cancer: Classification, histology and application of molecular pathology. J Gastrointest Oncol 2012;3:251-61.

8. Yusefi AR, Bagheri Lankarani K, Bastani P, et al. Risk Factors for Gastric Cancer: A Systematic Review. Asian Pac J Cancer Prev 2018;19:591-603.

9. Han L, Xin R, Sun J, et al. Association of single nucleotide polymorphisms of susceptibility genes of type 2 diabetes mellitus with liability to gout among ethnic Han Chinese males from coastal region of Shandong. Zhonghua Yi Xue Yi Chuan Xue Za Zhi 2015;32:711-4.

10. Wang FH, Shen L, Li J, et al. The Chinese Society of Clinical Oncology (CSCO): clinical guidelines for the diagnosis and treatment of gastric cancer. Cancer Commun (Lond) 2019;39:10.

11. Zaanan A, Bouché O, Benhaim L, et al. Gastric cancer: French intergroup clinical practice guidelines for diagnosis, treatments and follow-up (SNFGE, FFCD,
GERCOR, UNICANCER, SFCD, SFED, SFRO). Dig Liver Dis 2018;50:768-79.

12. National Health Commission Of The People's Republic Of China. Chinese guidelines for diagnosis and treatment of gastric cancer 2018 (English version). Chin J Cancer Res 2019;31:707-37.

13. Guideline Committee of the Korean Gastric Cancer Association (KGCA), Development Working Group \& Review Panel. Korean Practice Guideline for Gastric Cancer 2018: an Evidence-based, Multi-disciplinary Approach. J Gastric Cancer 2019;19:1-48. Erratum in: J Gastric Cancer 2019;19:372-3.

14. Japanese gastric cancer treatment guidelines 2018 (5th edition). Gastric cancer: official journal of the International Gastric Cancer Association and the Japanese Gastric Cancer Association. 2020.

15. Banks M, Graham D, Jansen M, et al. British Society of Gastroenterology guidelines on the diagnosis and management of patients at risk of gastric adenocarcinoma. Gut 2019;68:1545-75.

16. Peixoto RD, Rocha-Filho DR, Weschenfelder RF, et al. Brazilian Group of Gastrointestinal Tumours' consensus guidelines for the management of gastric cancer. Ecancermedicalscience 2020;14:1126.

17. Xiao Y, Jiang L, Tong Y, et al. Evaluation of the quality of guidelines for assisted reproductive technology using the RIGHT checklist: A cross-sectional study. Eur J Obstet Gynecol Reprod Biol 2019;241:42-8.

18. Cowl J, Tyrrell T, Sakala C, et al. G-I-N PUBLIC toolkit: patient and public involvement in guidelines. 2015.

19. Palda VA, Davis D, Goldman J. A guide to the Canadian Medical Association handbook on clinical practice guidelines. CMAJ 2007;177:1221-6. Erratum in: CMAJ 2007;177:1530.

20. AGREE Collaboration. Development and validation of an international appraisal instrument for assessing the quality of clinical practice guidelines: the AGREE project. Qual Saf Health Care 2003;12:18-23.

21. Larenas-Linnemann DES, Antolin-Amerigo D, Parisi C, et al. National clinical practice guidelines for allergen immunotherapy: An international assessment applying AGREE-II. Allergy 2018;73:664-72.

22. Yao X, Ma J, Wang Q, et al. A Comparison of AGREE and RIGHT: which Clinical Practice Guideline Reporting Checklist Should Be Followed by Guideline Developers? J Gen Intern Med 2020;35:894-98.

23. Chen Y, Yang K, Marusic A, et al. A Reporting Tool for Practice Guidelines in Health Care: The RIGHT 
Statement. Ann Intern Med 2017;166:128-32.

24. Enhancing the Quality and Transparency Of health Research. Available online: https://wwwequatornetworkorg/reporting-guidelines/right-statement/ (Accessed 28 July 2018).

25. Section of Gastrointestinal Surgery, Branch of Surgery, Chinese Medical Association, Section of Laparoscopic and endoscopic surgery, Branch of Surgery, Chinese Medical Association, Gastric Cancer Professional Committee, Chinese Anti-Cancer Association. Expert consensus and operation guide for digestive tract reconstruction in laparoscopic gastric cancer surgery (Version 2018). Chinese Journal of Practical Surgery 2018;38:833-9.

26. Section of Gastrointestinal Surgery, Branch of Surgery, Chinese Medical Association. Expert consensus and operation guide of pylorus preserving gastrectomy (Version 2019). Chinese Journal of Practical Surgery 2019;39:412-8.

27. Blair VR, McLeod M, Carneiro F, et al. Hereditary diffuse gastric cancer: updated clinical practice guidelines. Lancet Oncol 2020;21:e386-97.

28. Hamashima C. Update version of the Japanese Guidelines for Gastric Cancer Screening. Jpn J Clin Oncol 2018;48:673-83.

29. Muro K, Van Cutsem E, Narita Y, et al. Pan-Asian adapted ESMO Clinical Practice Guidelines for the management of patients with metastatic gastric cancer: a JSMO-ESMO initiative endorsed by CSCO, KSMO, MOS, SSO and TOS. Ann Oncol 2019;30:19-33.

30. Ono H, Yao K, Fujishiro M, et al. Guidelines for endoscopic submucosal dissection and endoscopic mucosal resection for early gastric cancer (second edition). Dig Endosc 2021;33:4-20.

31. Pimentel-Nunes P, Libânio D, Marcos-Pinto R, et al. Management of epithelial precancerous conditions and lesions in the stomach (MAPS II): European Society of Gastrointestinal Endoscopy (ESGE), European Helicobacter and Microbiota Study Group (EHMSG), European Society of Pathology (ESP), and Sociedade Portuguesa de Endoscopia Digestiva (SPED) guideline update 2019. Endoscopy 2019;51:365-88.

32. Voron T, Romain B, Bergeat D, et al. Surgical management of gastric adenocarcinoma. Official expert recommendations delivered under the aegis of the French Association of Surgery (AFC). J Visc Surg 2020;157:117-26.
33. Wong NACS, Amary F, Butler R, et al. HER2 testing of gastro-oesophageal adenocarcinoma: a commentary and guidance document from the Association of Clinical Pathologists Molecular Pathology and Diagnostics Committee. J Clin Pathol 2018;71:388-94.

34. Yao K, Uedo N, Kamada T, et al. Guidelines for endoscopic diagnosis of early gastric cancer. Dig Endosc 2020;32:663-98.

35. Chen RB, Chen YL, Gai GZ, et al. Analysis of reporting specification about sepsis practice guideline based on RIGHT standard. Zhongguo Zhong Yao Za Zhi 2017;42:1514-7.

36. Tejani T, Mubeen S, Seehra J, et al. An exploratory quality assessment of orthodontic clinical guidelines using the AGREE II instrument. Eur J Orthod 2017;39:654-9.

37. Radwan M, Akbari Sari A, Rashidian A, et al. Appraising the methodological quality of the clinical practice guideline for diabetes mellitus using the AGREE II instrument: a methodological evaluation. JRSM Open 2017;8:2054270416682673.

38. Sun W, An L, Bao X, et al. Consensus and controversy among severe pancreatitis surgery guidelines: a guideline evaluation based on the Appraisal of Guidelines for Research and Evaluation II (AGREE II) tool. Gland Surg 2020;9:1551-63.

39. Available online: http://www.right-statement.org/home/ extensions. (Accessed 28 July 2018).

40. Wang X, Chen Y, Yao L, et al. Reporting of declarations and conflicts of interest in WHO guidelines can be further improved. J Clin Epidemiol 2018;98:1-8.

41. Wang Q, Wang X, Chen Y, et al. Research gap of guidelines might be an important approach to prioritization (Letter commenting on: J Clin Epidemiol. 2015;68:341-6). J Clin Epidemiol 2016;69:251-2.

42. Yao L, Sun R, Chen Y, et al. The quality of evidence in Chinese meta-analyses needs to be improved. J Clin Epidemiol 2016;74:73-9.

43. Available online: http://www.right-statement.org/rightstatement/checklist. (Accessed 28 July 2018).

Cite this article as: $\mathrm{Wu} \mathrm{X,} \mathrm{Li} \mathrm{D,} \mathrm{Chen} \mathrm{H}$, Han J, Zhou H, He Z, Ma Y, Dong B, Wu Y, Matkowskyj KA, Ejaz A, Almhanna K, Wang Q. Evaluation of the reporting quality of guidelines for gastric cancer using the RIGHT checklist. Ann Transl Med 2021;9(12):1003. doi: 10.21037/atm-21-2491 


\section{Supplementary}

\section{Appendix 1 (Search Strategy)}

\section{PubMed search strategy:}

\#1. abdominal Neoplasms [MeSH]

\#2. Intestinal neoplasms [MeSH]

\#3. Stomach neoplasms $[\mathrm{MeSH}]$

\#4. Cancer* OR carcinoma* OR neoplasm* OR adenoma* OR adenocarcinom* OR tumour* ${ }^{*}$ tumor ${ }^{*}$ OR polyp* OR malignan* [Title/Abstract]

\#5. Digest* OR gastr OR gut OR epigastr* OR stomach* OR abdomen* OR intestine*[Title/Abstract]

\#6. \#4 AND \#5

\#7. OR \#1-\#3

\#8. \#6 or \#7

\#9. Guideline [Publication Type]

\#10.Practice Guideline [Publication Type]

\#11.guideline*[Title]

\#12.guidance*[Title]

\#13.recommendation*[Title]

\#14.OR \#9-\#13

\#15.\#8 AND \#14

\section{CBM search strategy:}

\#1 "胃癌 "[常用字段:智能 ] OR "贲门癌 "[常用字段 : 智能 ] OR "胃肿瘤 "[常用字段:智能 ] OR "贲门肿瘤 "[常用 字段:智能] OR "胃肿瘤 "[不加权: 扩展] OR "上消化 道肿瘤 "[常用字段 :智能]

\#2 "指南 "[常用字段: 智能] OR "推荐意见 "[常用字段 :智 能 ] OR "指南 "[不加权 :扩展 ]

\#3 (\#1 AND \#2)

\section{Wanfang database search strategy:}

\#1 主题:胃

\#2 主题:贲门

\#3 (\#1 OR\#2)

\#4 主题: 癌

\#5主题: 肿瘤

\#6 \#4or\#5

\#7 题名:(指南 or 推荐意见)

\#8 (\#6 and \#3) AND \#7

\section{CNKI search strategy:}

\#1 主题: 胃癌

\#2 贲门癌

\#3 胃肿瘤

\#4 贲门肿瘤
\#5 上消化道肿瘤

\#6 OR \#1-\#5

\#7 题名: 指南

\#8 题名: 推荐意见

\#9 \#7 OR \#8

\#10 \#6 AND \#9 